\title{
AS RELAÇÕES DE TRABALHO E A AÇÃO GERENCIAL: UM ESTUDO EM BANCOS PRIVADOS ${ }^{1}$
}

\section{THE RELATIONS OF WORK AND THE MANAGEMENTAL ACTION: A STUDY IN PRIVATE BANKS}

\author{
Helltonn Winicius Patrício Maciel ${ }^{2}$ \\ Anielson Barbosa Silva ${ }^{3}$
}

\begin{abstract}
RESUMO: Este artigo objetiva analisar os vínculos entre as relações de trabalho e a ação gerencial no setor financeiro. O estudo é uma reflexão sobre as implicações das transformações ocorridas nas relações de trabalho decorrentes das mudanças ocorridas no contexto dos bancos. A pesquisa possui caráter qualitativo e analisa as experiências de gerentes e supervisores que trabalham em bancos privados da cidade de Campina Grande/PB. A análise dos resultados favorece a uma reflexão crítica da subsunção dos trabalhadores gerentes em meio à pressão multidimensional exercida sobre os mesmos. O gerente bancário se vê predominantemente numa realidade marcada pelo uso da autoridade formal como meio para o atendimento de interesses organizacionais. A não aceitação de argumentos em meio a problemas operacionais, as constantes pressões para o alcance das metas sobre o risco de ser demitido comprometem o exercício da atividade gerencial. O medo de perder o emprego e de errar leva o gerente a se submeter a situações que caracterizam um processo de precarização das relações de trabalho.
\end{abstract}

PALAVRAS-CHAVE: relações de trabalho; gerentes; bancos privados.

ABSTRACT: This article examines the links between work relations and management action in the financial sector. The study is a reflection on the implications of changes in the work relations resulting from changes in the banks context. The research is qualitative and examines the experiences of managers and supervisors who work in private banks in the Campina Grande/PB city. The results favor a critical reflection of subsumption workers managers in the midst of multidimensional pressure exerted on them. The bank manager is seen predominantly in a reality marked by the use of formal authority as a means to attend to organizational interests. The rejection of arguments in the midst of operational problems, the constant pressure to achieve the goals of the risk of being dismissed undertake the managerial activities exercise. The fear of losing his job and make e mistake takes the manager to submit to conditions that characterize a process of deterioration of work relations.

KEY-WORDS: work relations; managers, private banks.

\footnotetext{
${ }^{1}$ Artigo Recebido em 10.01.2010. Revisado por pares em 18.10.2011. Recomendado em 10.10.2011 por Edson Roberto Scharf - Editor Responsável. Publicado em 13.06.2012.

Organização Responsável pelo periódico: Universidade Regional de Blumenau - FURB - www.furb.br/rn
}

\footnotetext{
${ }^{2}$ Universidade Federal da Paraíba - UFPB - hw_cg@ hotmail.com

${ }^{3}$ Universidade Federal da Paraíba - UFPB - anielson@uol.com.br
} 


\section{INTRODUÇÃO}

As transações financeiras seguem o movimento da mundialização do capital, cujas operações atingem o mais alto grau de mobilidade, uma vez que é mais notória a defasagem entre as prioridades dos operadores e as necessidades mundiais. Não é por acaso que diversos grupos industriais deram visibilidade e relevância às operações especulativas. A divergência entre a taxa de crescimento das atividades financeiras e das atividades produtivas é um reflexo, ainda que imperfeito, da dinâmica própria dos mercados financeiros.

Chesnais (1996) considera o regime de acumulação mundial predominantemente financeiro e Arrighi apud Jinkings (1996) destacam que a massa de capital é revertida para a sua forma monetária e é direcionada para empréstimos e especulação para gerar mais dinheiro, o que se entende por capital fetichizado (MARX, livro III, capítulo XXIV). As relações sociais ficam totalmente mistificadas e o capital toma a aparência de dinheiro que gera mais dinheiro.

Contudo, o capital financeiro pode ser considerado como um filho rebelde que nega suas origens e deseja viver por contra própria sem dar satisfação aos "pais" mas, ainda, de forma contraditória, recebe a "mesada" de sua parentela. Esta analogia é pertinente ao passo que o capital financeiro surgiu a partir do lucro do setor produtivo de forma direta ou indireta, continua se nutrindo do capital produtivo e por si mesmo a esfera financeira não cria nada. Apesar de sua importância, as atividades do setor produtivo se colocam em condição subalterna (CHESNAIS, 1996).

Para Marx (livro III, capítulo XXIV) a acumulação dos lucros financeiros representa a forma mais alienada e mais fetichizada da relação capitalista, entendendo-se fetichizada como uma expressão que representa a geração de dinheiro sem a sua devida passagem pelo setor produtivo.

A dívida pública é outro vetor que engrandece a supremacia do setor financeiro, surgindo assim uma nova classe rentista que vive da detenção de ativos da dívida pública que capta rendimentos por via fiscal, como observa o Fundo Monetário Internacional (FMI), de forma categórica, mas que remete a um desespero contido para a consciência dos que possuem bom senso. "Os títulos públicos representam a espinha dorsal dos mercados de obrigações mundiais. Seu volume de transações supera, de longe, o de qualquer outro segmento dos mercados financeiros, com exceção dos mercados de cambio" (CHESNAIS, 1996, p. 248).

No setor financeiro, ocupado em grande parte por bancos privados, os gerentes que trabalham nestas instituições são extremamente pressionados para cumprir as metas impostas para garantir um nível de remuneração e manter um padrão de vida. O objetivo deste artigo consiste em analisar os vínculos entre as relações de trabalho e a ação gerencial em instituições bancárias. O estudo aborda aspectos como o autoritarismo presente na cultura organizacional brasileira e suas implicações na flexibilidade e nas relações entre gestores e funcionários, além de aspectos vinculados ao relacionamento interpessoal, ao medo e ao sofrimento no contexto da ação profissional. 


\section{REFERENCIAL TEÓRICO}

As organizações brasileiras enfrentaram inúmeros desafios nos últimos anos, especialmente a partir do processo de abertura econômica iniciado na primeira metade da década de 1990. O acirramento da disputa dos mercados tem motivado a busca de um padrão de competitividade de classe mundial, e não é diferente para os trabalhadores do setor bancário. Devido aos modelos de gestão importados, o Brasil, por conta da sua história e da influência de diversos povos no processo de colonização, formou uma identidade singular. Assim, investigar essa realidade é tarefa obrigatória para todos os interessados em desenvolver atividades no país. Organizações atentas a isso têm superado problemas e crescido com consistência (TANURE, 2007).

Tanure (2007) defende a existência de três pilares na cultura brasileira: o poder, as relações e a flexibilidade. No Brasil, o poder é mais concentrado, com forte origem patriarcal, não deixando dúvidas sobre quem é o responsável pela decisão nem sobre quem deve implementar o que foi decidido. A percepção dos gerentes é que as relações de poder ainda estão muito marcadas pelo significado da autoridade. Por outro lado, o desejo das pessoas de participarem de um sistema mais descentralizado ou diminuir a distância de poder entre chefe e subordinado também aumentou, contribuindo para que a percepção relativa do grau de distância de poder continuasse a mesma.

Embora os regimes de gestão centralizados possuam certa rapidez no processo decisório, tal administração acarreta no não-comprometimento das pessoas. O ideal é um líder democrático que saiba descentralizar o processo decisório. As decisões brasileiras, mais rápidas e arriscadas com um número menor de participantes, utilizam um numero igualmente menor de informações, provocando uma maior dificuldade para o alcance de objetivos, comparativamente ao processo decisório inglês (MOTTA, 2001; TANURE, 2007).

Nas sociedades individualistas, valoriza-se quem diz o que pensa, enquanto nas emocionais o mais importante é expressar o que se sente. Na típica cultura brasileira evita-se o conflito com quem tem mais poder, pois os que ocupam uma posição de menor poder fogem do embate, uma vez que querem preservar a estrutura das relações pessoais ameaçada em um confronto direto e aberto. Por outro lado, segundo Tanure (2007), os que ocupam as posições mais altas não evitam conflitos com a mesma intensidade.

A flexibilidade apresenta duas faces logo percebidas pelos estrangeiros que vêm ao Brasil: a adaptabilidade e a criatividade. Segundo Tanure (2007), adaptabilidade é a capacidade de se ajustar a constantes mudanças de regras; a criatividade está associada à inovação e se manifesta, por exemplo, em festejos populares. No Brasil, apesar de baixos níveis estruturais, mesmo com a pobreza e a disparidade de renda, há sempre quem surpreenda pela capacidade de adaptação e inovação, constituindo-se numa grande habilidade de conviver com os opostos.

O bom entendimento das organizações brasileiras inicia-se no desenvolvimento singular dos traços de nossa cultura. Traços nacionais são parte do inconsciente de cada individuo (FREITAS, 1997).

Tanure (2007) e Freitas (1997) abordam aspectos envolvendo o poder e enfatizam a concentração excessiva na mão de líderes que centralizam todo o conjunto, deixando apenas os próprios líderes como a fonte para tomar todas as decisões. Os autores também relacionam 
personalismo e relações: de um lado, os menos favorecidos de poder obedecem para não haver nenhum tipo de conflito com seus líderes e interagem de forma que se relacionem bem com todos e vivem sem se chocar de frente com os chefes; por outro lado, há proximidade e afeto nas relações. Na verdade, seria uma forma de manter seus empregos e, em contrapartida, ter a devida valorização das suas idéias. A comparação entre a Flexibilidade e Malandragem, que é a forma de se dar um jeitinho em tudo e ter flexibilidade às mudanças, se houver, e estar sempre disposto a inovar, não aderindo à mesmice. Nem todo jeitinho é um procedimento correto, mas uma forma de indisciplina, como por exemplo, adiar a realização de tarefas.

A cultura influencia a ação gerencial no contexto das instituições financeiras. Além disso, outros aspectos inerentes à subjetividade do ser gerente também devem ser considerados como balizadores de suas ações.

\subsection{Ser gerente: indivíduo e subjetividade}

O gerente é agente que possui características bem peculiares, pois se trata de um indivíduo que, de acordo com Davel e Mello (2005), se encontra entre a concepção e a ação, ou seja, é aquele sujeito da empresa, que está localizado entre a alta direção, que estabelece as diretrizes, o planejamento e as estratégias de longo prazo e os subordinados que executam as atividades operacionais. Dado o seu caráter intermediário, o gerente sofre pressões dos dois lados, de forma mais enérgica da alta cúpula empresarial e/ou de forma mais reivindicante dos subordinados que questionam as exigências e a quantidade das metas.

Hill (1999) afirma que os novos gerentes se deparam com quatro tarefas transformacionais complexas: aprender o que significa ser um gerente, gerar um julgamento interpessoal, lidar com tensões e emoções e obter conhecimento. Assim, o novo gerente tem que aprender a gerenciar a equipe e o contexto em que ela se encontra. Ter credibilidade em vez de apenas autoridade formal, tentar obter o comprometimento do funcionário e não querer controlá-lo e liderar a equipe em vez de gerenciar indivíduos. Mas como conseguir tal aprendizado numa realidade cuja cultura organizacional possui nuanças de autoritarismo? Como afirma Tanure (2007), o autoritarismo prejudica o envolvimento dos subordinados.

Há gerentes informais que não possuem a autoridade instituída, mas adquirem a confiança da equipe. Então, cabe ao gestor ter competência, caráter e influência para estabelecer a confiança entre os membros e liderá-los (HILL, 1999). Cada contexto pode exigir uma atitude. Muitas vezes o gerente deve ser mais racional e rotineiro, assim como precisa ser mais inovador, ou seja, há necessidade de adaptação do estilo de liderança ao contexto, baseando-se na abordagem contingencial (BOWDITH; BUONO, 2002).

No estudo da compreensão do que os executivos fazem em seu trabalho, Henry Mintzberg (1990) estudou o cotidiano dos gerentes e delimitou dez papéis gerenciais classificados como: interpessoais, informacionais e decisórios. Os papéis interpessoais dizem respeito ao relacionamento pessoal, dentre elas aponta-se o de figurão (envolve aspectos de representação em eventos), o de gerente (estimular o comprometimento dos funcionários) e o de ligação (ser o intermediário das relações). Os papéis informacionais se referem à difusão de informações, entre elas destaca-se o papel de monitor (receptor de dados), de disseminador (emissor de conhecimentos) e de porta-voz (encaminhar as informações entre os grupos). E os papéis decisórios se referem à tomada de decisão, subdivididos em empreendedor 
(responsável pelas mudanças), solucionador de distúrbios (apaziguador), distribuidor de recursos (alocador de materiais e mão de obra) e negociador (realiza acordos).

Dessa maneira, Mintzberg (1990) transcende às atividades gerenciais dispostas no conceito das funções gerais da administração (planejar, organizar, dirigir e controlar), agregando maior relevância à ação gerencial. No contexto bancário, o desempenho depende da compreensão de como agir no dia-a-dia, com sua equipe, os seus pares, clientes, governo e partes interessadas, ou seja, com todos os agentes internos e externos à organização.

Em um estudo realizado com gerentes bancários, Silva (2005) descreve as transformações ocorridas na atividade gerencial de profissionais que atuam em uma instituição bancária.

Para os gerentes pesquisados, o contexto da mudança favoreceu o surgimento de conflitos entre a prática gerencial e as relações em família, uma vez que passou a demandar mais tempo de dedicação dos gerentes para o trabalho em detrimento da família, além da necessidade de qualificação profissional visando se adequar às competências desejadas a um cargo gerencial. O contexto e os fatores determinantes delimitam atributos essenciais na prática gerencial e são ilustrados no quadro 6.

\begin{tabular}{|l|l|}
\hline O CONTEXTO DA PRÁTICA GERENCIAL & FATORES DETERMINANTES DA PRÁTICA \\
GERENCIAL
\end{tabular}

Quadro 6: O espaço social da prática gerencial

Fonte: Silva, 2005, p. 198.

O contexto e os fatores determinantes da prática indicam que as transformações ocorridas na organização afetaram a maneira de agir do gerente no contexto de sua ação profissional. Os fatores determinantes estão associados à competências interpessoais e à valorização das pessoas, além de atributos clássicos como liderança e trabalho em equipe. Os gerentes precisam estar disponíveis para ouvir, mas também precisam ser objetivos para entender e diagnosticar problemas na equipe e possuir habilidade para escolher as ações mais apropriadas para ajudar a alcançar as metas da equipe (HILL, 2004).

O gerente coordena uma equipe de trabalho e existem, segundo Hackman e Walton (1986), três critérios necessários para a efetiva execução das atividades em equipes organizacionais: direção clara (metas) e atrativa; recursos materiais adequados e um contexto organizacional (cultura) que apóie e reforce a excelência. Porém, a realidade da cultura da maior parte das empresas brasileiras está envolvida de um caráter autoritário que dificulta tal envolvimento (HILL, 2004; YUKL, 1998; TANURE, 2007). É mister que as metas das equipes sejam claras e que as pessoas avaliem se o desempenho esperado foi alcançado (HOUSE; MITCHELL, 1974 apud BOWDITH; BUONO, 2002). Portanto, o gerente precisa manter a equipe focada nas metas e encontrar a melhor estrutura para realizá-las. 
O gerente, de acordo com Hill (2004), para alcançar a devida efetividade de sua equipe, precisa agir por meio de processos cognitivos, motivacionais, afetivos e de coordenação. A cognição do gerente auxilia a equipe a entender os problemas e discuti-los, enquanto a motivação faz com que a equipe fique mais unida e seja capaz de se ajudar mutuamente para alcançar o desempenho. Já a afetividade do gerente equilibra e controla as situações de stress e a coordenação auxilia na integridade das habilidades dos membros da equipe, provendo as estratégias claras, monitorando-as e avaliando-as conforme o contexto.

McClelland (1985), citado pelos autores Bowdith e Buono (2002), afirma que líderes eficazes não têm necessidades sociais muito intensas, e devem ser capazes de trabalhar independentemente. Entretanto, Barnard (1971) afirma que na liderança os gerentes são essencialmente impotentes até que seus seguidores lhe concedam o poder de conduzir. Mintzberg (1990) corrobora com as idéias de Barnard visto que nos papéis gerenciais existem aqueles voltados para os aspectos interpessoais.

Mas gerente e líder são sinônimos? Zaleznick (1977) distingue as atividades dos lideres e dos gerentes. O primeiro seria mais ativo, inovador, assumiria as posições de alto risco e odiaria as atividades rotineiras. Enquanto o segundo seria mais racional e controlado, reativo, solucionador de problemas e criativo. Contudo, discorda-se dessa segmentação, pois uma característica não cessa a outra, uma vez que cada contexto pode exigir uma atitude. Muitas vezes o líder deve ser mais racional e rotineiro, bem como o gerente precisa ser mais inovador, ou seja, há necessidade de adaptação do estilo de liderança ao contexto, baseandose na abordagem contingencial e multidimensional, uma vez que há muito de líder em ser gerente e vice-versa (BOWDITH e BUONO, 2002; SILVA 2005) e este é o posicionamento adotado neste trabalho.

No contexto da atividade gerencial no setor financeiro, o gerente, assim como todas as pessoas, possui sua devida subjetividade que é arraigada por uma infinidade de sentimentos que afetam diretamente no seu desempenho e nas relações entre a concepção e a ação, numa relação, muitas vezes conflitante. Um desses sentimentos é o sofrimento.

Para Dejours (1994), o sofrimento presente no contexto organizacional se vincula a dados relativos à história singular de cada indivíduo e aos aspectos referentes à sua situação atual, delimitando uma dimensão temporal que implica na delimitação de processos pelo próprio trabalhador no âmbito de sua atividade. $\mathrm{O}$ autor distingue dois tipos específicos de sofrimento: o primeiro é o patogênico e o segundo o criativo. O patogênico se inicia no momento em que foram explorados todos os recursos defensivos do indivíduo. Esse tipo de sofrimento é uma espécie de resíduo não compensado, que leva a uma destruição do equilíbrio psíquico do sujeito, empurrando-o para uma lenta e brutal destruição orgânica.

No momento em que a organização do trabalho se torna autoritária, ocorre um bloqueio da energia pulsional, que se acumula no aparelho psíquico do indivíduo, gerando desta forma, sentimentos de tensão e desprazer intensos. A carga psíquica do trabalho resulta da confrontação do desejo do trabalhador, à injunção do empregador contida da organização do trabalho. Em geral, a carga psíquica do trabalho aumenta quando a liberdade de organização do trabalho diminui (DEJOURS, 1994, p. 28).

Quanto ao segundo tipo, Dejours (1994) denomina de sofrimento criativo pelo fato de o indivíduo elaborar soluções originais que favorecem ou restituem sua saúde. $\mathrm{O}$ sofrimento 
criativo chega a adquirir um sentido, pois favorece ao indivíduo um reconhecimento de uma identidade. Neste contexto, o indivíduo se propõe a ação criativa que promove descobertas, fazendo com que este experimente e transforme, de maneira criativa, prática e astuciosa, soluções inéditas frente às situações móveis e cambiantes de seu trabalho. A competência e a astúcia, promovida pela inteligência coletiva ou individual, proporcionam o surgimento de estratégias defensivas, que aliviam ou combatem o sofrimento psíquico.

O sentimento de medo traz muitas limitações aos gerentes e a sua disseminação impossibilita saídas coletivas e conduz a saídas individuais como mecanismo de defesa, desaguando na decisão pela adesão a sistemas muitas vezes exploradores de trabalho devido ao crescente desemprego que bate às portas da atualidade. O medo pode gerar uma vivência de ruptura dos contratos psicológicos e das relações de trabalho vigentes e provocam mudanças de natureza afetiva que se faz pela imposição e não mais pelo respeito (CALDERON, 2000).

Por serem os que movimentam bilhões e bilhões de dólares e capitais que transitam a cada dia, de um país para outro, os mercados financeiros tornaram-se ao mesmo tempo, polícia, juiz e júri da economia mundial, o que não deixa de ser preocupante, dada sua propensão os acontecimentos e as políticas através das lentes deformantes do medo e da cobiça (FINANCIAL TIMES, 1994 apud CHESNAIS, 1996, p.237).

Chesnais (1996) revela a percepção geral do poderio das instituições financeiras que controlam a gestão das diversas agências espalhadas por todo o mundo, colocando-as em condição de hegemonia frente a todo o contingente de trabalhadores do setor que são submetidos a um trabalho intenso para obter uma maior remuneração ou pelo medo de se tornar um desempregado (CALDERON, 2000). Todavia, ao despertar tais sentimentos, os bancários, enquanto categoria profissional, visam também à sua proteção como um mecanismo de inibição da exploração excessiva do trabalhador bancário e do incentivo à maior participação deste nos lucros da empresa. Para aprofundar a compreensão sobre o sujeito gerente bancário é interessante abordar o contexto da ação desse profissional.

\subsection{Os gerentes bancários, os sindicatos e a sua subserviência ao capital financeiro}

As mudanças nas formas pelas quais o capital assegura a própria reprodução prejudicam a classe trabalhadora e o movimento sindical se confronta com entraves para sua ação e resistência. Exacerbando a fragmentação e estimulando praticas segregadoras entre os bancários, a reestruturação nos bancos exclui do mercado àqueles que não possuem o perfil para a função, ou seja, não estão adequados aos padrões de produtividade e qualidade das instituições financeiras.

Os programas de qualidade total e de remuneração variável desenvolvem um conjunto de estratégias que conseguem o envolvimento e a adesão de cada bancário ao ideário patronal, aprofundando a dominação capitalista do trabalho bancário. Os programas premiam saltos de produtividade de forma pontual congelando a parcela fixa do salário. Os bancários se tornam dependentes do crédito oferecido pelos bancos (cheque especial, cartão de crédito, empréstimos), muitas vezes utilizados até para cobrir diferenças de caixa das suas próprias funções. A função bancária oferece muitos benefícios, mas em longo prazo não são incorporados ao trabalho, muito menos na aposentadoria dos profissionais, mostrando assim o 
caráter imediatista de tais benefícios e das remunerações variáveis que os mesmos recebem (JINKINS, 2006).

Para as direções sindicais, as ações grevistas convertiam-se em lições práticas da dinâmica de luta do trabalho contra a dominação capitalista, justamente por causa da dominação dos bancos no ideário dos bancários que acabam por sucumbir a um individualismo e ao descrédito das lutas coletivas por causa da agregação da remuneração variável aos gastos mensais dos mesmos. Corroborando com esta idéia, um dirigente sindical entrevistado no trabalho de Nise Jinkings (2002, p.303) afirma:

É uma luta árdua, processo de convencimento, de diálogo com os trabalhadores, superdificil, supercomplexo, um individualismo muito grande entre os trabalhadores, um descrédito muito grande de que a luta coletiva, a luta social possa trazer algum retorno.

O contexto mais geral de mudança econômica e política do Brasil e seus reflexos no sistema financeiro nacional somam-se às transformações nas formas de organizações e controle do trabalho, decorrentes da reestruturação produtiva, criam barreiras ao desenvolvimento da luta sindical, aumentando o poder de barganha dos bancos por meio da remuneração variável que os gerentes recebem, a qual chega a dobrar seus rendimentos no mês. Desta forma, o principal mecanismo de controle utilizado pelos bancos faz com que os gerentes exerçam maior poder de barganha para os funcionários e sofram também por saber que dependem daquela remuneração variável para pagar o custo de seu padrão de vida (JINKINS 2002). Outro agravante ao trabalho bancário é a longa jornada de trabalho aos quais os mesmos se submetem, em função do volume de ações que a justiça recebe de exbancários que ganham valores expressivos por causa do trabalho, além do limite de duas horas extras por dia de trabalho. Algumas chegam até mesmo a trabalhar 12 horas segundo depoimentos de advogados que recebem as causas que encaminham a justiça. (ALVES, 2005).

\section{METODOLOGIA DE PESQUISA}

O estudo se classifica como qualitativo, visto que nesse tipo de pesquisa os investigadores acadêmicos estão interessados em compreender fenômenos sociais, focalizando os significados construídos pelos sujeitos a partir das experiências como foram vividas ou sentidas (MINAYO, 1994).

A pesquisa também pode ser classificada como exploratória, que segundo Vergara (2007) é uma pesquisa que tem como objetivo proporcionar maior familiaridade com o estudo, focando o aprimoramento de idéias ou a descoberta de intuições. Seu planejamento é, portanto, bastante flexível, de modo que possibilita a consideração dos mais variados aspectos relativos ao fato estudado.

Para a escolha dos sujeitos da pesquisa, utilizou-se a amostragem por julgamento, que segundo Malhotra (2001) consiste numa forma de amostragem não probabilística por conveniência, em que os elementos da população são selecionados com base no julgamento 
do pesquisador, a afinidade de relacionamento. Além do fato de que as entrevistas se deram fora o ambiente de trabalho. Desta forma, a acessibilidade e a veracidade e maior espontaneidade para as entrevistas foi critério para a escolha dos entrevistados que constituíram um total de treze entrevistados: dez gerentes e três supervisores de operações que são classificados como gerentes informais (HILL, 1999), sendo todos funcionários de três dos maiores bancos privados na cidade de Campina Grande.

A coleta de dados foi realizada utilizando a entrevista semi-estruturada com questões abertas padronizadas, nas quais os entrevistados têm a liberdade de emitir a sua opinião sobre as perguntas realizadas pelo pesquisador (VERGARA 2007). Foi elaborada uma carta de apresentação entregue a cada um dos entrevistados. Todos concordaram voluntariamente em participar da pesquisa e validaram seus discursos após a leitura das transcrições das entrevistas.

As perguntas centrais da entrevista abordaram aspectos da cultura organizacional brasileira, a subjetividade do ser gerente e da análise do ambiente bancário as quais se desdobraram nas seguintes variáveis:

\begin{tabular}{|c|c|c|}
\hline CATEGORIA & VARIÁVEL & AUTOR \\
\hline \multirow{2}{*}{ Cultura organizacional } & Relações de autoritarismo & \multirow{2}{*}{$\begin{array}{lll}\text { TANURE } & \text { (2007); } & \text { FREITAS } \\
(1997) & & \end{array}$} \\
\hline & Flexibilidade/malandragem (ambiente de trabalho) & \\
\hline \multirow{4}{*}{$\begin{array}{l}\text { A subjetividade do ser } \\
\text { gerente }\end{array}$} & $\begin{array}{l}\begin{array}{l}\text { Percepção dos colaboradores em relação ao } \\
\text { gerente }\end{array} \\
\end{array}$ & HILL (1999) \\
\hline & $\begin{array}{l}\text { Cognição, motivação e } \\
\text { Afetividade }\end{array}$ & HILL (2004) \\
\hline & Sofrimento & DEJOURS (1994) \\
\hline & Medo & $\begin{array}{ll}\text { CALDERON, } & (2000) ; \\
\text { CHESNAIS, }(1996) & \end{array}$ \\
\hline O ambiente bancário & Subsunção ao capital e fragmentação sindical & JINKINGS (2006) \\
\hline
\end{tabular}

Quadro 1 - Categorias utilizadas na Pesquisa.

Fonte: Elaborado pelos autores, 2010.

O processo de análise e tratamento dos dados seguiu os procedimentos estabelecidos por Minayo (1994). Todas as entrevistas foram gravadas em áudio e transcritas literalmente. A primeira etapa do processo envolveu a ordenação das entrevistas, por meio da codificação dos discursos dos gerentes. Cada um dos pesquisados recebeu um código. Os gerentes foram codificados como G1, G2, G3, G4, G5, G6, G7, G8, G9 e G10 e os Supervisores de operações como S1, S2, e S3. Nos Bancos A e B foram entrevistados três gerentes e um supervisor. No Banco $\mathrm{C}$ foram entrevistados quatro gerentes e um supervisor.

Após a coleta e transcrição das entrevistas, iniciou-se a segunda etapa do processo com o objetivo de classificar os dados, que envolveu a análise das respostas dos gerentes, visando identificar os significados presentes em suas falas. Minayo (1994, p. 78) afirma que

nessa fase é importante termos em mente que o dado não existe por si só. Ele é construído a partir de um questionamento que fazemos sobre eles, com base na fundamentação teórica. 
Através de uma leitura exaustiva e repetida dos textos, estabelecendo interrogações para identificarmos o que surge de relevante (MINAYO, 1994, p. 78).

Em seguida, foi realizada a análise final, procurando estabelecer articulações entre os dados das sete entrevistas e o referencial teórico para analisar os vínculos entre as relações de trabalho e a ação gerencial nos bancos pesquisados. O objetivo é promover uma "relação entre o concreto e o abstrato, o geral e o particular, a teoria e a prática (MINAYO, 1994, p. 79).

\section{RESULTADOS DA PESQUISA}

Os resultados da pesquisa revelam que apesar de algumas peculiaridades de cada banco, houve similaridade e complementaridade na percepção dos gestores. No que se refere às relações de autoridade, percebe-se que os gerentes são pressionados pelos superiores para atingir as metas, por meio de uma relação de submissão do gerente em relação ao superior. Sete dos gerentes entrevistados emitem declarações que ratificam a sua inserção em um ambiente em que as relações de trabalho são mediadas pelo elevado nível de exigência, a falta de respeito e de consideração, onde se valoriza mais o que se pensa em detrimento ao que se sente, demonstrando o uso do poder de forma autoritária e unilateral.

“... é muito difícil lidar com essas relações de autoridade, porque muitas vezes sou visto como alguém que cobra demais, mas eu também sou muito exigido pelo superintendente regional, a pressão que exercem sobre nós é enorme, já ouvi muito a famosa frase "Se não conseguem fazer arrume alguém que consiga", e o pior é que eu já falei isso em reunião. Sei que não é a forma mais adequada para mobilizar as pessoas, mas é o que acontece. Certa vez recebemos uma multa por causa da demora nas filas e fui repassá-la para o meu gestor, sendo que nesse dia, tínhamos enfrentado sérios problemas com o nosso sistema operacional. $\mathrm{O}$ meu diretor não quis saber se o sistema estava funcionando ou não, ele me disse que eu deveria resolver, dessa forma fica difícil passar compreensão e colaboração para os meus funcionários se constantemente sou tratado desta forma”. (Depoimento G2)

“...já fui chamada de "burra" pelo meu superior porque ele dizia que eu não estava entendendo o que ele estava dizendo, mesmo que isso só tenha ocorrido uma vez, fiquei profundamente magoada com aquilo e nunca mais o questionei sobre quaisquer meta a cumprir e quando não cumpria apenas recebo os sermões indiretos que ele faz". (depoimento G1)

“...me sinto numa situação extremamente desconfortável com meu gerente de operações, ele exige muito de mim para que ele receba todo o crédito. Certa vez eu estava numa ação interna de venda de cartões ajudando o pessoal de vendas quando o gerente chegou e disse: "e ai? Já cumpriu a meta? Corra com isso ai se não EU não recebo a minha variável". Eu trabalho exaustivamente apenas pra ele receber a remuneração variável? E o meu reforço? Não conta?”. (Depoimento S2)

"dizem que há uma gestão por equipes, eu até escuto os funcionários, eles participam das discussões, vemos as dificuldades que eles têm, e tento na medida do possível ajudá-los não em redefinir os objetivos, mas em compensá-los, com brindes, jantares, mas no final o fato é a 
verdade da diretoria e do que ela exige, não vejo um esforço por parte da diretoria em me escutar como faço com meus funcionários" (Depoimento G6).

"Toda semana tenho reuniões com o gerente geral, cansei de escutar dele frases irônicas, ou mesmo indiretamente ameaçadoras, coisas do tipo: para quem não cumprir a meta não se preocupe, pois eu tenho uma gaveta cheia de currículos para analisar" (Depoimento G7)

Os relatos indicam que os gerentes vivenciam dificuldades no exercício de sua função, pois são constantemente pressionados pelos seus superiores, pelo uso da autoridade formal com o objetivo de fazer com que os interesses pessoais associados a resultados sejam atendidos, G10 ainda salientou que já ouviu de um colega também gerente que o mesmo foi humilhado pelo seu superior com a seguinte frase: "Você não está adequado sequer para serviços braçais". Dessa forma, a pressão vinda de cima é acatada pelo gerente, e devido a sua constante atuação, repassada para os funcionários, caracterizando um ambiente de cobrança exaustiva, de preconceito, de submissão, de um relacionamento de autoritarismo e agilidade no processo decisório, porém acompanhado do desgaste das relações interpessoais.

Para auxiliar a constatação do poder autoritário, G4 fez menção a um folhetim sindical da época de aquisição de um dos bancos estudados. Diante das cláusulas do processo de aquisição apresentadas, percebe-se que os funcionários sofreram um grande autoritarismo, pois tiveram que abrir mão dos seus próprios direitos para que o Banco fosse reaberto e assim permanecerem com seus empregos:

“...os funcionário dos Empregadores e sindicatos da categoria bancária renunciaram ao questionamento de quaisquer parcelas remuneratórias devidas e não pagas até a data de assinatura do "acordo" de aquisição, como bem colocado pelo presidente do banco, se não fosse o acordo o banco não teria sido reaberto, e assim todos estariam nas ruas, o que não impediu que ao longo do tempo alguns ainda fossem demitidos". (Depoimento G4)

As relações de confiança são testadas em momentos de crise, quando muitos são polidamente ameaçados de demissão, sobretudo nos casos de empresas em que as relações não são sólidas, podendo assim refletir a desconfiança ou a ausência de confiança. A responsabilidade mútua se traduz na percepção da necessidade de alguém pela ajuda do individuo, proporcionando a este último um significado de importância para si e para a organização. Todavia, o capitalismo neoliberal, em que a relação entre risco e recompensa é pequena, muitos são demitidos sem uma reflexão sobre o papel e a importância do funcionário para a empresa. "A falta de responsividade é uma reação lógica ao sentimento de que não somos necessários"(SENNET, 2006, p 175). A corrosão do caráter se expressa justamente ai, na percepção da não serventia para a sociedade e de que as pessoas são facilmente substituíveis (SENNET, 2006).

Um dos gerentes pesquisados (G3) se mostrou mais habilidoso com relação à forma de repassar para os funcionários as exigências a serem cumpridas. Nesse discurso, percebe-se que a tensão não é repassada aos colaboradores, mas internalizada pelo gerente, o que pode provocar vários problemas físicos, de saúde e interferir em seu comportamento dentro e forma da agência bancária. $O$ gerente utiliza a palavra imposição como uma forma de uso da autoridade como fonte de tensão e que está intimamente relacionada a resultado. 
“...procuro não repassar para meus funcionários a mesma carga de estresse que o meu diretor me transfere, pois não gosto de tratar as pessoas como não gostaria de ser tratado. Cedo espaço para que todos participem da minha gestão, claro que há momentos de grande estresse no cumprimento das metas, mas no geral consigo filtrar as imposições da diretoria". (Depoimento G3)

Em relação à flexibilidade, todos os entrevistados reforçam que é preciso a disponibilidade do gestor para se adequar as novas mudanças nas agências. Um dos gerentes ressaltou que o mesmo já foi transferido para 4 agências em 10 anos na função de gerente. As tecnologias utilizadas pelos bancos estão em contínuo processo de otimização. Por isso, todos os funcionários, sobretudo os gerentes, devem se adaptar aos novos sistemas bancários que lhe são disponibilizados.

“ quando se é gerente, e você veste a camisa da empresa, não há como negar uma "oportunidade" de transferência, pois a sua imagem enquanto gestor fica prejudicada para com a diretoria, você fica visado como alguém que trava o processo, que não é flexível" (depoimento G8)

"meu trabalho é flexível sim, tenho liberdade de me ausentar da agência para visitar clientes sem precisar pedir autorização para isso, porém tal flexibilidade é vigiada pelos demais colegas. Se faço muitas visitas no mês, começo a ser indiretamente ironizado por outros colegas gerentes com frases do tipo: Passei pelo seu local de trabalho e não te vi, liguei para seu terminal e apenas chamava...o que sinto é que com esses comentários, na verdade eles queriam era me criticar por estar fora do meu posto" (depoimento G10)

No depoimento de um dos gerentes há o alerta sobre um grave problema da realidade de trabalho presente em nossa época. Relata o gerente: "Já ouvi colegas que diziam que mentir ou omitir para o cliente não é errado, é estratégia. Já vi muitos colegas gerentes que aumentavam o limite dos clientes sem quaisquer consulta ao mesmo na intenção de alcançar determinada meta”. Um dos gerentes confirmou categoricamente que muitas vezes é obrigado indiretamente a mentir, segundo ele: "Trabalhar no banco afeta a minha religiosidade". Esses relatos indicam um comportamento incoerente com a ética profissional, que muitas vezes pode ser adotado em detrimento do alcance de metas institucionais.

A partir do momento em que os sujeitos da própria organização mentem ou omitem para o cliente e não são considerados errados, em decorrência de uma estratégia para crescimento no mercado, pode provocar uma grande alteração nas condutas realizadas pelos indivíduos, tornando a mentira um artifício para conquistar posições, caracterizando uma possível adaptação de um indivíduo a um determinado grupo (o grupo daqueles que conseguem cumprir as metas), contextualizadas as devidas particulares. O comportamento ético, nesse contexto, não pode ser balizado pelos interesses, mas ser mediado pelos valores e pela moral.

Uma questão direcionada para os supervisores (S1 e S2) teve como objetivo analisar a sua atuação informal como gerente que participa, ainda que com um caráter de coadjuvante, das relações entre a gerência e os demais trabalhadores bancários. 
“...apesar de ser um supervisor, já escutei diversas vezes que já tenho potencial pra ser um gerente de operações, inclusive sempre substituo o gerente operacional quando mesmo entra de férias. E isso acaba por fortalecer as minhas ações perante os outros funcionários, eles confiam mais nas minhas concepções, sou sempre muito solicitado para tirar qualquer dúvida sobre normas do banco. O problema é que muitas vezes essa oportunidade não aparece, já estou a 5 anos nessa função... Fica-se apenas no campo das promessas, e às vezes sinto um pouco de frustração nisso". (Depoimento $\mathrm{S} 1$ )

“...a confiança existe. O problema é que a promoção para gerente demora muito, normalmente são um ou dois supervisores nas agências do banco, e um gerente administrativo. Enquanto que na área de vendas é o quíntuplo de gerentes de vendas e triplo de subgerentes (que se equivalem a supervisores)". (Depoimento S2)

A adoção de confiabilidade gerencial a S1 e S2 demonstra que mesmo não possuindo o cargo de gerência, eles são legitimados pelos demais funcionários para agir como tal. Porém, percebe-se que o fato da promoção ser sempre algo demorado, (o que pode ser ocasionado por uma rigidez no plano de carreira como relata S2) não alcançar um cargo gerencial gera sentimentos de descontentamento com relação a uma promoção que nunca surge.

A efetividade das equipes envolve a delimitação de processos (HILL, 2004). G2 demonstrou que cede espaço para que seus funcionários participem da gestão, mas o único problema para ele é o alcance de metas, cuja negociação fica a desejar por causa do diretor da Regional. Exceto G3, todos os demais afirmam que a maioria da resolução dos conflitos existentes ocorre por meio de práticas que provocam um elevado nível de competição, que segundo Robbins (2005) apesar de trazerem resultados imediatos, são desaconselháveis ao uso freqüente em longo prazo, pois desgastam as relações entre os funcionários:

"a todo momento estamos competindo com os colegas das outras agências, como se já não bastasse a concorrência entre os colegas dos outros bancos, competimos entre nós mesmos constantemente, muito mal-estar já foi gerado por conta disso, já fiquei meses sem falar com alguém da outra agência porque ele tinha invadido o local de atuação da minha agência em campanhas de certo produto"

Para os entrevistados, o processo de auxílio no entendimento dos problemas, união para se alcançar determinado desempenho e o equilíbrio das relações de estresse ficam extremamente comprometidos. O entrevistado G3 afirmou de forma categórica que as metas são coletivas e que a colaboração entre os funcionários de seu setor é sempre mais utilizada que a competição individual. Porém, ele afirma que nessas metas coletivas sempre há uma vigilância e cobrança mútua para o alcance dos resultados que são mensurados pelo desempenho geral do setor. Uma questão procurou identificar os aspectos do sofrimento no trabalho de Dejours (1994).

“...como gerente de operações, é descrito no cargo que ocupo que possuo a autonomia de realizar as promoções de que a agência onde trabalho necessita. Certa vez, eu tinha uma funcionária caixa excelente, há muito trabalhava na função e sempre que necessário substituía a tesoureira em quaisquer eventualidades. Esta tesoureira foi promovida e eu gostaria de colocar aquela funcionária caixa como tesoureira. No entanto, recebi um comunicado da 
superintendência dizendo que a vaga seria preenchida por alguém escolhido por eles, veio então um funcionário de outra cidade para ocupar a vaga e não possuía a mesma habilidade e conhecimento que a funcionária caixa tinha. Eu sofro junto com ela, pois não tive a devida liberdade para reconhecer alguém de grande competência”. (Depoimento G2).

"São muitas metas a serem atingidas, dos mais diversos tipos, cartão de crédito, conta corrente, retenção de clientes, seguros, capitalizações... muitas foram as noites mal dormidas pensando nas metas que tinha que cumprir, na prova específica sobre conhecimentos bancários que tinha que estudar, e todas, no longo prazo, passíveis de demissão." (Depoimento G9)

“...o problema são as reuniões de final de expediente com a superintendência regional pela teleconferência, além de serem quase que diárias, são muito demoradas e eu sempre chego atrasado na universidade, os meus diretores não entendem que eu tenho atividades acadêmicas que devo cumprir, eu sinto meu aprendizado na universidade prejudicado, por chegar na metade da aula com o assunto a pleno vapor. São muitas informações que me são difíceis de assimilar justamente por sair atrasado do curso. Já me foi até oferecida uma vaga na diretoria mais pra isso tenho que terminar a graduação em administração. Se pelo menos meus diretores tivessem a devida compreensão de me deixar sair mais cedo da teleconferência para assistir aula já me seria de grande ajuda". (Depoimento G5)

Percebe-se que G2 teve sua liberdade de organização do seu setor seriamente atingida, aumentando assim a sua carga psíquica de trabalho. G2 confirmou que muitas de suas dores de cabeça foram causadas devido a ocasiões como a que foi relatada. G1 confirmou que a pressão exercida sobre ela faz com que reflita em formas criativas para atingir suas metas. Segundo a gerente, o período de campanha de abertura de contas correntes universitárias proporciona condições para que ela possa agir de forma inovadora, mas muitas vezes teve que realizar o trabalho fora do seu horário de expediente, o que a desgasta e transforma aquela criatividade em cansaço e estafa. Portanto, aquele sofrimento criativo que a mesma possuía é convertido em sofrimento patológico devido à exploração do trabalho bancário.

G5 e G9 ainda revelam que o sofrimento é provocado pela pressão para conquistar uma gama diversa de metas, de cumprir exigências de qualificação interna, de concluir o curso de graduação para ser promovida e da necessidade de estar presente nas reuniões após o expediente. As exigências impostas pela diretoria não convergem, fazendo com que G5 e G9 sofram constantemente com a cobrança contraditória.

Em relação ao medo no ambiente de trabalho, todos os entrevistados afirmaram que um de seus medos é de ficar desempregado, de não poder sustentar seus familiares e essa sensação acaba levando-os a "vender" a sua força de trabalho capital, o que eleva o nível de exploração do trabalho do gerente bancário pelos bancos, que almejam aumento na sua rentabilidade. Os gerentes, com exceção do G3, afirmam ter medo de errar e assumir a falha, de perder a imagem que construíram antes de serem devidamente promovidos, pois como gerentes eles se vêem numa situação que não lhes é permitido cometer enganos. "Se eu demonstrar fraqueza, como posso repassar a garra necessária para o cumprimento das metas? E mesmo errando, procuro formas alternativas de concertar o meu erro sem necessariamente expô-lo para minha equipe de trabalho" (Depoimento G2). G3 disse que "errar é humano, o 
que não podemos é persistir no erro, o fato de errar e assumir para todos pedindo as devidas desculpas não me diminui, pelo contrário me ajuda a ter mais credibilidade com o pessoal".

A última questão (a qual aborda as ações gerencias e sua relação com a categoria que o representa, ou seja, o sindicato bancário) possui uniformidade de sentido em todas as respostas como indicam os relatos a seguir. "O que posso fazer? Eu dependo muito mais da variável que recebo pelo cumprimento das metas do que da diferença salarial que recebo das reivindicações do sindicato" (S1). "E eu já pago uma taxa todo mês para que eles me representem, não preciso ficar indo ao piquete em período de greve, eles não já fazem todo o trabalho de reivindicação?” (S2).

“...lembro-me como se fosse hoje, estávamos em período de greve, e eu estava substituindo o gerente geral da agência que estava de férias, devido as constantes pressões pelo alcance de metas eu precisava de pelo menos um funcionário da área comercial para me ajudar, mas o pessoal do sindicato foi enérgico em não permitir que ele entrasse na agência, respondi de forma enfática e em alto tom que quem mandava naquela agência era eu e que eu colocava quem eu quisesse para entrar." (Depoimento G3).

"...período de greve sempre é um sufoco, ficamos "rodando" no centro da cidade visitando clientes até que o sindicato terminasse o piquete na porta da agência, daí entramos depois das 16h para poder lançar no sistema todas as atividades advindas das visitas e dentre outras pendências". (Depoimento G1).

“...é engraçado que durante as ultimas negociações sindicais poucos eram os funcionário da rede privada que compareciam às reuniões. Eu era um deles, mas no ano passado, no dia decisivo para se saber se a categoria iria entrar de greve ou não, uma massa pesada de gerentes apareceu lá votando contra a greve, tive um colega gerente de contas que foi praticamente "intimado" a participar para votar contra a paralização por tempo indeterminado" (Depoimento S1).

“...acho o discurso sindical muito inspirador, afinal são pessoas que estão engajadas para nos representar frente aos banqueiros, gostaria de participar mais das reuniões, mas é impossível pra mim, são reuniões constantes no banco para saber como estão o alcance das metas, como foi a produção daquele dia, além dos estudos da faculdade, fora a minha família em casa a qual cuido, quer dizer, não há como eu estar mais integrado a minha classe". (depoimento G4).

"Nos períodos de greve, para mim não muda muita coisa, pois como trabalho na área de operações internas do banco, constantemente sou solicitado pelo gerente para fazer as operações internas, já vi discussões acaloradas entre o gerente e o pessoal do sindicato." (depoimento S3)

Vivencia-se hoje a era das competências, em que o indivíduo é mais valorizado que o cargo que o mesmo ocupa. Todavia, tanto valor atribuído a este indivíduo prejudica a sua ação coletiva enquanto categoria de trabalhadores. No setor financeiro, ocupado em grande parte por bancos privados, tal realidade é ainda mais acentuada, e os bancários são extremamente pressionados para cumprir as metas impostas e garantir aquela remuneração extra em prol da manutenção seu padrão de vida. Remuneração esta que é superior ao valor reajustado por mês em seu salário advindo de um exaustivo e complicado processo de reivindicação do sindicato bancário. Para alguns, o próprio sindicato existe para servir ao 
bancário, deturpando o verdadeiro sentido de união de uma classe para a instauração de um "pseudocontrato" de prestação de serviço, o que contribui para a deturpação do ideal de união da classe bancária. Este individualismo é resultante do neoliberalismo que leva os gerentes a serem forçados a agir em contraponto com as reivindicações da categoria, trabalhando em períodos de greve, esperando o piquete sair para assim poderem entrar na agência e realizar suas atividades. (FISCHER, 2002; FRANÇA, 2007; ULRICH, 2000; MARRAS, 2005; AMARO, 2008; MACIEL, 2010).

No confronto diário dos trabalhadores bancários com o capital nos seus locais de trabalho, a realidade contraditória do mundo produtivo manifesta-se numa mesclagem de ações de resistência e subordinação ou adesão desses trabalhadores à lógica capitalista. As relações sociais calcadas na busca contínua pela mais valia dificultam a apreensão da vida cotidiana em seus nexos de colaboração e integração. (JINKINGS, 1996, p.28)

Sindicatos bancários buscam por um aumento da melhoria salarial e muitas vezes tal incremento se encontra fragilizado pela divisão e não cooperação de sua categoria, que se divide entre bancos públicos e privados. Mesmo que atuem em bancos privados ou não, existe uma disparidade nas relações de trabalho entre os bancos, caracterizada pelas diferenças nas políticas de participação nos lucros dos gerentes que não são compatíveis com o volume de trabalho, considerando também as outras funções como escriturários, caixas, tesoureiros, etc. Surgem facções dentro da própria agência bancária que rompem com a união daqueles trabalhadores, a partir do momento em que as recompensas de alguns supera em mais de $100 \%$ as da grande maioria, fazendo com que muitos se calem em meio ao sistema explorador e neoliberal dos bancos. Sem falar do próprio medo do desemprego que abafa o clamor de reinvindicação de muitos trabalhadores do setor bancário. (JINKINGS, 1996; ALVES, 2005)

O principal mecanismo de controle utilizado pelos bancos faz com que os gerentes exerçam maior poder de barganha para os funcionários e sofram também por saber que dependem daquela remuneração variável para pagar o custo de seu padrão de vida (JINKINS 2002; MACIEL, 2010).

\section{CONSIDERAÇÕES FINAIS}

O capitalismo arraigado por sua faceta mais recente - o neoliberalismo, coloca o homem numa posição tendenciosa ao individualismo e um dos fatores que contribuem para esse processo é a auto-regulação de alguns mercados, nos quais a produção e a distribuição são controladas pelos preços, pois é a partir destes que são gerados os rendimentos necessários para a redistribuição dos bens para a sociedade, estabelecendo assim um "equilíbrio de mercado" fundamentado nos conceitos de Justiça e Igualdade. Contudo, Cardoso (1999) não corrobora com tal argumento, afirmando que a eficiência do sistema não se dá a partir da equidade de distribuição, pois há como meta a satisfação de agentes auto-interessados, além do fato da justiça ocorrer em uma sociedade de colaboração e não em competitividade que é um dos cernes do mercado auto-regulado. Para o autor: "Nenhum dos agentes econômicos tem incentivos para mudar sua própria estratégia de ação a menos que outro o faça [...] ninguém pode estar em melhor posição sem piorar a posição de um terceiro ou vice-versa ( $p$ 95-96)." 
E esta realidade competitiva e concentrada influencia a prática do gerente bancário que, enquanto ser humano cuja função é praticar sua natureza social, por vezes, é condicionado a agir corroído pelo sistema ao qual esta inserido (POLANYI, 1980; SENNET, 2006).

O gerente bancário se vê predominantemente numa realidade autoritária, cujas decisões são resolvidas em processos que envolvem sobreposições de funções: o desejo de promoção frustrado, a não aceitação de argumentos em meio a problemas operacionais, as constantes pressões para o alcance das metas sobre o risco de ser demitido comprometem a atuação dos devidos papéis dos gerentes principalmente no que tange aos interpessoais. $\mathrm{O}$ fator do medo do descrédito da instituição perante possíveis falhas também se mostrou expressivo na pesquisa, como também o medo de perder o emprego e assim não poder sustentar os seus familiares.

Para Sennett (2006), o ambiente de trabalho moderno - com ênfase nos trabalhos em curto prazo, na execução de projetos e na flexibilidade - não permite que as pessoas desenvolvam experiências ou construam uma narrativa coerente para suas vidas. E, mais importante, esta nova forma de trabalho impede a formação do caráter, pois, para este autor, o desenvolvimento do caráter depende de virtudes estáveis, como lealdade, confiança, comprometimento e ajuda mútua, características que estão desaparecendo no novo capitalismo.

Os laços fortes, em contraste, dependem da associação em longo prazo. E, mais pessoalmente, da disposição em estabelecer compromissos com os outros agentes. A dissolução da classe trabalho dificulta o estabelecimento de laços, sobretudo em diversas empresas terceirizadas, pelo ritmo e forma de trabalho impostos, cedendo espaço para que as práticas individualistas e que envolvam a malandragem ocorram.

Apenas um dos entrevistados revelou que trabalha num clima organizacional que incentiva o trabalho em equipe e os diálogos em um processo de gestão participativo. Mesmo assim, este gerente vivencia conflitos, pois precisa usar mecanismos para amenizar toda uma carga de pressão que a diretoria exerce sobre ele. Em termos de sofrimento, todos os entrevistados demonstraram que a criatividade advinda de uma liberdade no exercício da função é prejudicada pela intervenção da diretoria nas competências gerenciais, levando ao agravamento do sofrimento patológico dos mesmos.

Por fim, percebe-se o grande impacto que a remuneração variável exerce sobre a classe gerencial ao ponto de fragmentá-los de sua categoria em períodos de reivindicação. A busca da flexibilidade produziu novas estruturas de poder, controle, e discórdia em vez de criarem as condições que libertam os profissionais do setor bancário. O sistema de poder que se esconde nas modernas formas de flexibilidade intensifica a dominação subjetiva do trabalhador, tornando-o obediente a todo o sistema e o fazendo opositor da própria classe que o representa nos momentos em que o trabalho ou a comissão estão em risco.

Dentre as dificuldades encontradas, a mais expressiva foi a falta de tempo disponível para aprofundar a análise dos resultados. Apesar das entrevistas terem sido feitas fora do expediente bancário, a vida pessoal dos gerentes também é repleta de outros compromissos. Pondera-se por fim, que o estudo pôde estimular uma maior reflexão sobre a realidade dos gerentes no setor bancário e, de forma análoga, possibilita o surgimento de estudos futuros mais críticos sobre o assunto envolvendo, por exemplo, trabalhar com o sentimento de 
frustração de tais profissionais e o seu impacto para a organização, além de aprofundar aspectos sobre a emoção no contexto da ação de profissionais do setor financeiro, sobretudo nos bancos.

\section{REFERÊNCIAS}

ALVES, A. E. S. Qualificação e trabalho no contexto da reestruturação produtiva. Vitória da Conquista: Edições Uesb, 2005.

AMARO, R. de A. Da qualificação à competência: deslocamento conceitual e individualização do trabalhador. RAM - Revista de Administração Mackenzie, V. 9, N. 7 Nov/dez, 2008.

BARNARD, C. As funções do Executivo. São Paulo: Atlas, 1971.

BOWDITH, J.L.; BUONO, A. F. Elementos do Comportamento Organizacional. São Paulo: Pioneira, 2002, cap. 7 (liderança e gerência).

CALDAS, M. P. (Org). Cultura organizacionl cultura brasileira. São Paulo: Atlas, 1997.

CALDERÓN, R. do C. dos S. Desemprego e subjetividade: um estudo sobre programas de demissão voluntária. Dissertação (Mestrado em Psicologia) - Programa de PósGraduação em psicologia, Universidade de São Marcos, São Paulo, 2000.

CARDOSO, A. M. Sindicatos, trabalhadores e a coqueluche neoliberal: a era Vargas acabou? Rio de Janeiro: Ed FGV, 1999.

CHESNAIS, F. - A mundialização do capital. Tradução Silvana Finzi Foá São Paulo: Ed Xamã 1996

DAVEL, E.; MELLO, M. C. O. Gerência em ação: singularidades e dilemas do trabalho gerencial. Rio de Janeiro: FGV, 2005

DEJOURS, C; et al. Psicodinâmica do Trabalho. São Paulo: Atlas, 1994. 145p.

FISCHER, A L. As Pessoas nas organizações. São Paulo: Gente, 2002.

FRANÇA, A. C. L. Práticas de recursos humanos. São Paulo: Atlas, 2007.

FREITAS, A. B. Traços brasileiros para uma análise organizacional. In: MOTTA, F. C. P.;

HACKMAN, J. R. e WALTON, R. E. «Leading groups in organizations». In GOODMAN, P. S. Designing Effective Work Groups. São Francisco: Editora Jossey Bass, 1986.

HILL, L. A. Desenvolvendo as estrelas do desempenho. In: HESSELBEIN, F.; COHEN, P.M. De líder para líder. São Paulo: Futura, 1999. 
HILL, S.E.K. Team Leadership. In: NORTHHOUSE, P. G. Leadership: Theory and Pratice. 3 ed. Thousand Oaks: Sage Publications, 2004. Cap. 10, p. 203-234.

JINKINGS, N. O mister de fazer dinheiro. São Paulo: Ed Boitempo, 1996.

JINKINGS, N. Trabalho e resistência na fonte misteriosa: os bancários no mundo da eletrônica e do dinheiro. São Paulo: Ed Unicamp, 2002.

MACIEL, H. W. P. As relações de trabalho nos bancos privados: um estudo dos impactos da política de gestão e seus impactos sobre os bancários. 2010, 115 fls. Dissertação (Mestrado em Administração) - Programa de Pós-graduação em Administração, UFPB, João Pessoa, PB.

MALHOTRA, N. Pesquisa de Marketing: uma orientação aplicada. 3. ed. Porto Alegre: Bookman, 2001.

MARRAS, Jean Pierre - Gestão de Pessoas em empresas inovadoras. São Paulo: Ed Futura 2005

MARX, K. O Capital. Livro 1. São Paulo: editora Nova cultural, 1996.

MINAYO, M. C. de S. (ORG.) Pesquisa social: teoria, método e criatividade. $10^{\mathrm{a}}$.ed. Petrópolis, Vozes, 1994.

MINTZBERG, H. The manager's Job: Folklore and Fact. Haward Business Review, vol. 6, n. 8, mar./apr. 1990.

MOTTA, Paulo Roberto. Transformação organizacional. A teoria e a prática de inovar. São Paulo: Qualitymark, 2001.

POLANYI, Karl. A grande transformação: as origens de nossa época. Ed Campus, 1980.

ROBBINS, S. P. Comportamento organizacional. 11. ed. São Paulo: Pearson, 2005.

SENNETT R. A corrosão do caráter: conseqüências pessoais do trabalho no novo capitalismo. Tradução: Marcos Santarrita 11 ${ }^{\mathrm{a}}$ ed Rio de Janeiro: Ed Record, 2006.

SILVA, A. B. A vivência de conflitos entre a prática gerencial e as relaçoes em família. 2005. 272 fls. Tese (Doutorado em Engenharia de Produção, Universidade Federal de Santa Catarina, Florionópolis, 2005

TANURE, B.; EVANS, P. ; PUCIK, V. A gestão de pessoas no Brasil. Rio de Janeiro: Campus, 2007.

ULRICH, Dave. Recursos Humanos Estratégicos, Novas perspectivas para os profissionais de RH. São Paulo Ed Futura 2000 
VERGARA, S. C. Projetos e relatórios de pesquisa em administração. $9^{a}$ ed. São Paulo: Atlas 2007.

YUKL, G. Leadership in Organizations. News Jersey (USA): Prentice Hall, 1998. Cap. 14 (Leadership in teams and self-manages groups), p. 351-379.

ZALEZNICK, A. Managers and leaders: are they different? Harvard Bussiness Review, p. 67-78, may./ jun. 1977. 